\title{
$\underline{\text { Case Reports }}$
}

\section{A case of diffuse neonatal haemangiomatosis}

\author{
V P Wickramasinghe ${ }^{1}$, S P Lamabadusuriya ${ }^{2}$, P A S S Dayawansa ${ }^{3}$
}

Sri Lanka Journal of Child Health, 2004; 33: 87-8

(Key words: diffuse neonatal haemangiomatosis)

\section{Introduction}

Haemangiomata are benign vascular tumours occurring during neonatal period. Multiple haemangiomata occur in about $25 \%$ of patients with haeman-gioma ${ }^{1}$. If they occur only in the skin, the entity is termed benign neonatal haemangiomatosis ${ }^{2}$. If the haemangiomata show systemic involvement, including visceral heaemangiomata, the term diffuse neonatal haemangiomatosis is used ${ }^{3}$.

\section{Case report}

A seven month old baby boy from Heyyanthuduwa (Gampaha district) presented with multiple cutaneous haemangiomata. The child is the second product born to non-consanguineous parents. He was delivered vaginally at Kandy Teaching Hospital, at 32 weeks of gestation. Birth weight was $1.75 \mathrm{~kg}$. and perinatal period was uneventful. The child developed multiple haemangiomata on face and trunk during the late neonatal period (Figure 1). Although medical advice was sought, they were reassured. There were no other dysmorphic features

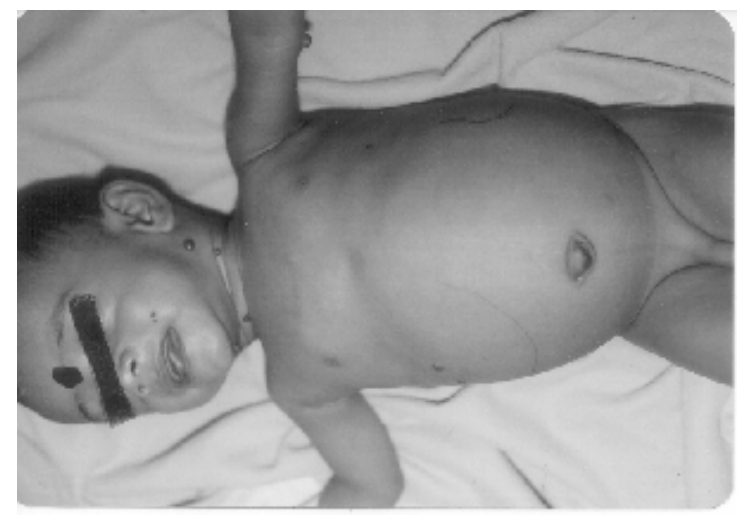

Figure 1. Diffuse cutaneous haemangiomata

${ }^{1}$ Lecturer, ${ }^{2}$ Senior Professor, Department of Paediatrics, Faculty of Medicine, University of Colombo, ${ }^{3}$ Registrar in Paediatrics, Lady Ridgeway Hospital, Colombo.

(Received on 28 December 2003)
At about five and a half months of age child developed lower respiratory tract infection and was treated at Kandy Teaching Hospital. Child was detected to be having pallor with hepatosplenomegaly. The haemoglobin $(\mathrm{Hb})$ was $5.1 \mathrm{~g} / \mathrm{dl}$ and he required a packed cell blood transfusion.

The platelet count was $210 \times 10^{9} / \mathrm{L}$ and ESR $32 \mathrm{~mm}$ in the 1 st hour. Child was investigated for a possible haemolytic anaemia. However, investigations were normal (reticulocyte count 1\%, alkaline denaturation test $0.7 \%$ and $\mathrm{Hb}$ electrophoresis normal with $\mathrm{Hb} \mathrm{\textrm {A } _ { 2 }}$ $2.2 \%$ ). Child's growth and development was satisfactory. The colour of his stools was normal. Parents brought the child to Colombo for further management.

Multiple cutaneous haemangiomata with hepatomegaly of $5 \mathrm{~cm}$ and splenomegaly of $4 \mathrm{~cm}$ prompted the possible diagnosis of diffuse multiple haemangiomatosis. Possible explanation for anaemia was an occult blood loss. Repeated investigations showed a $\mathrm{Hb}$ of $10.7 \mathrm{~g} \%$, WBC of $9.2 \times 10^{9} / \mathrm{L}$ and differential count of N44\%, L55\% and E1\%. Platelet count was $235 \times 10^{9} / \mathrm{L}$. Stool occult blood was negative. Ultra-sound scan (USS) of abdomen showed multiple haemangiomata in liver (Figure 2) and right kidney.

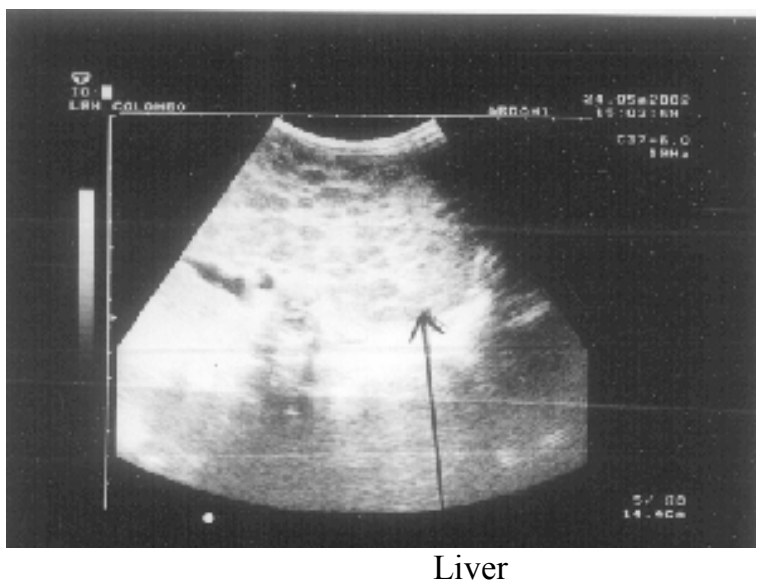

Figure 2. Ultra sound scan of abdomen 
A CT scan of the abdomen was done and showed extensive involvement of liver and a small haemangioma in spleen (Figure 3)

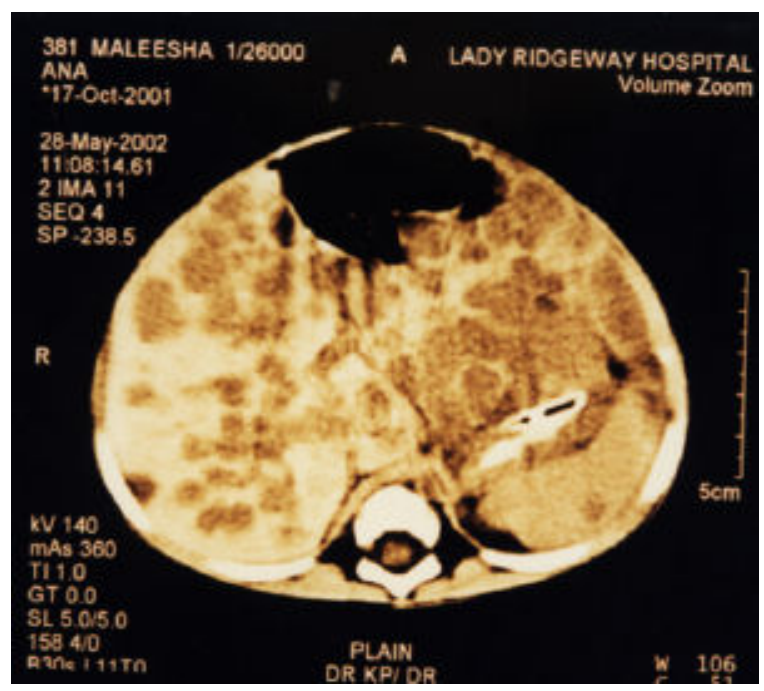

Figure 3. CT scan of abdomen

No further blood transfusions were required. He was started on steroids $(2 \mathrm{mg} / \mathrm{kg}$ body weight in two divided doses) and repeated US scans of abdomen were done to assess the response to treatment. Even after 3 months of steroid therapy there was no appreciable clinical or USS improvement. However, the $\mathrm{Hb}$ remained normal and there was no further enlargement of liver or spleen. Steroids were continued for 5 months and as there was no clinical improvement of the hepatosplenomegaly, the steroid treatment was stopped. Child was referred to a plastic surgeon to attend to the cutaneous haemangiomata.

When child was re-examined 5 months after stopping the steroids, the liver had regressed to a size of $2 \mathrm{~cm}$ below the costal margin and the spleen was just palpable. The USS of abdomen showed a significant improvement in the liver and no haemangiomata were seen in the spleen.

\section{Discussion}

In diffuse neonatal haemangiomatosis the haemangiomata can occur in the eye, lung, liver or bowel. They can lead to high output congestive cardiac failure or haemorrhage from viscera ${ }^{2,3,4,5}$. Mortality is reported to be as high as $81 \%$ without treatment and $29 \%$ with treatment. Usually high output failure, visceral haemorrhage or seizures would lead to death. Haemangiomata could be associated with many other dysmorphic syndromes ${ }^{3}$.
Therapeutic interventions depend on the number, site of the lesions as well as the interference to normal function of viscera. Many haemangiomata involute spontaneously without any treatment and often have a better cosmetic result than if early surgery had been rendered $^{3}$. High dose corticosteroids, intralesional steroids and interferon alpha (INF- $\square$ ) have all being used with success ${ }^{3}$.

\section{Acknowledgements}

We thank Dr. K Pathirana and Dr. I N A Gooneratne, Consultant Radiologists of Lady Ridgeway Hospital for the assistance given in doing the CT and USS.

\section{References}

1. Achaeuer $\mathrm{B} \mathrm{M}$, Chang $\mathrm{C}$, Vander $\mathrm{V} \mathrm{M}$. Management of hemangiomas of infancy: Review of 245 patients. Plastic Reconstruction Surgery 1997; 99: 1301-8.

2. Held J L, Haber R S, Silvers D N et al. Benign neonatal hemangiomatosis: Review and description of a patient with unusually persistent lesions. Pediatric Dermatology 1990; 7: 63-6.

3. Dohil M A, Baugh W P, Eichenfield L F. Vascular and pigmented birth marks. Pediatric Clinics of North America 2000; 47: 783-812.

4. Boon L M, Burrows $\mathrm{P}$ E, Paltiel $\mathrm{J} H$ et al. Hepatic vascular anomalies in infancy: A twenty seven year experience. J Pediatrics 1996; 129: 346-54.

5. Golitz L E, Rudikoff J, O'Meara O P. Diffuse neonatal haemangiomatosis. Pediatric Dermatology 1986; 3: 145-52. 
